КУНЯШОВА Светлана Владимировна магистр культурологии, аспирант кафедры культурологии Астраханского государственного университета, Астрахань, Российская Федерация Svetlana V. KUNYASHOVA Master of Cultural Studies, Postgraduate Student, Astrakhan State University, Astrakhan, Russian Federation, svet.3107@mail.ru

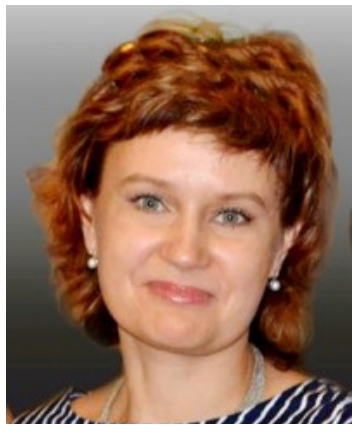

\section{Объекты культурного наследия Астраханской области в системе региональной культурной политики}

\section{Cultural Heritage of Astrakhan Oblast in the Regional Cultural Policy}

Проблема сохранения и эффективного использования культурного наследия той или иной страны сложна и многоаспектна. Перед Россией, столкнувшейся в постсоветский период с рядом кардинальных перемен в различных сферах, в том числе и в культурной, она стоит особенно остро. Решение данной проблемы является одним из важнейших направлений культурной политики государства и каждого его отдельно взятого региона. В этом смысле интересен опыт Нижнего Поволжья - региона, представляющего собой поликультурное пространство. На его примере автор статьи, применив метод кросскультурного анализа, исследовала состояние региональных объектов культурного наследия и возможность их использования. В результате были выявлены как положительные тенденции, характеризующие региональную культурную политику в части сохранения и популяризации культурного наследия, так и реальные проблемы, нерешенность которых порой приводит к полному исчезновению некоторых объектов из-за их хищнической эксплуатации или замены их симулякрами. Кроме того, автором был предложен модульный подход к изучению культурного ландшафта и выделены базовые модули культурного наследия города Астрахани и Астраханской области.

Ключевые слова: культурное наследие, культурная политика, поликультурный регион, симулякр, культурный менеджмент, модульный подход.

Введение. Культурное пространство современного мира невозможно представить без культурного наследия, являющегося «сложным соединением материальных и нематериальных элементов культуры, обладающих совокупностью ценностей, которая значима своим многообразием» $[8$, с. 61]. Культурное наследие - это то, что «подлежит сохранению в настоящем ради возможности потребления в будущем» $[17$, p. 12]. 
Говоря об упомянутом феномене, мы должны учитывать не только его аксиологическую, но также социальную, экономическую и пр. значимость, что особенно важно для поликультурных регионов, этно-конфессиональная множественность которых создает сложный социокультурный ландшафт. При грамотной культурной политике именно объекты культурного наследия могут стать на таких территориях платформой для налаживания диалога между представителями разных народов, чтобы они могли лучше понять друг друга, найти общезначимые для всех жителей региона ценности и т.п. Более того, способы и механизмы сохранения культурного наследия становятся маркером уровня развития общества, отражая его социальную зрелость (или наоборот). От эффективности разработанной стратегии сохранения культурного наследия может зависеть способность общества соответствовать социально-экономическому уровню цивилизованных стран. В силу этого культурное наследие любого, и особенно полиэтнического, региона требует тщательного и постоянного изучения.

\section{Специфика культурного наследия} Астраханской области. Астраханская область всегда отличалась своей этнокультурной неоднородностью, отсутствием аборигенного населения и постоянными миграционными потоками. Такой регион можно назвать гетеротопным [16, р. 22]. Его население является носителем нескольких уровней идентичности - этнического, регионального, конфессионального, общероссийского, что, с одной стороны, создает условия для взаимодействия народов, формируя региональный, наднациональный тип культуры, но с другой - такое культурное многообразие крайне неустойчиво, и чем выше степень «пестроты», тем больше рисков этноконфликтных ситуаций.

Благоприятная атмосфера для культурного диалога складывалась в Астрахани постепенно, на протяжении нескольких веков. Через эту землю, ещё в старину названную «Вратами Евразии», проходили многочисленные торговые пути. Она влекла представителей разных народов. Частично оседая здесь, они взаимодействовали, ассимилировались и со временем начинали ощущать себя частью отдельной общности, которую впоследствии назовут «астраханцами». Это определило своеобразие развития Нижнего Поволжья как перекрестка культур и религий, духовное наследие которого поистине уникально.

Астрахань - это не только река Волга, гора Богдо, соляное озеро Баскунчак и лотосовые поля Прикаспия. Это ещё и удивительная архитектура, представляющая собой сложный синкретизм православных храмов и монастырей, синагог и католических соборов, многочисленных мечетей, рядом с которыми некогда располагались индийское, персидское, армянское торговые подворья, лютеранская кирха, армянский собор и восточные банки.

Что-то было уничтожено временем, но большая часть сооружений сохранилась, и сегодня на территории Астрахани находится более 500 памятников [10, с. 102] различных исторических периодов и различной ценности, в совокупности создающих неповторимый колорит южного города, являющегося в буквальном смысле «узлом частей света: Запада и Востока» [4, с. 35]. Вбирая в себя элементы культуры разных народов, здесь постепенно складывалась единая региональная культура, и её носители - все астраханские этносы - «принимали общие правила игры, в основе которых лежало принятие другой нации как равной. И это позволяло и позволяет им сохранять статус-кво» [7, с. 18]. Астраханцы с детских лет чувствуют на себе влияние многих языков, культур, обычаев, обрядов, что способствует формированию мультикультурной личности с высоким уровнем толерантности.

Правда, стоит отметить, что относительное этнокультурное равновесие, сложившееся в регионе, было нарушено перестроечными процессами 90-х гг. XX в., сопровождавшимися ростом этнического самосознания, вызвавшего возрождение этнокультурных традиций и вслед за этим этноконфессиональное противостояние. Ситуация усугубилась притоком мигрантов из южных постсоветских республик, а также из конфликтных регионов Российской Федерации.

В регионе начали появляться новые скульптурные и архитектурные объекты, слабо вписывающиеся в общекультурный ланд- 
шафт Нижнего Поволжья, мало известные населению и порождающие негативную переоценку существующих общерегиональных ценностей. Речь идет о различных интерпретациях, а порой даже фальсификации исторических фактов в интересах того или иного этноса или религиозной конфессии. Культурные сигнификаты (как федеральные, так и региональные) стали приобретать открыто этноконфессиональную окраску, что отразилось на репрезентации «своего» наследия. Данная ситуация ведет не только к культурной, но и к социальной нестабильности и, безусловно, требует внесения соответствующих корректив в культурную политику государства.

Некоторые из них уже налицо. Так, в 2018 г. запущен Национальный проект «Культура» (2019-2024 гг.), который впервые «возводит культуру в ранг национальных приоритетов» [5]. Проект направлен на достижение «качественно нового состояния инфраструктуры культуры» [11] и предполагает сделать сохранение культурного наследия локомотивом экономического и социального развития регионов России, вовлекая существующие ресурсы в экономическую и туристическую сферы, что должно повысить инвестиционную привлекательность региона. Астраханская область славится разнообразием своего культурного наследия, поэтому по всем параметрам подходит для реализации данного проекта.

С этой целью на кафедре культурологии Астраханского государственного университета на протяжении нескольких лет комплексно изучались механизмы мемориализации и забвения культурного наследия региона, обладающего некой «срединностью» между западной и восточной, европейской и азиатской культурами [2]. Результатом исследований стал новый фундаментальный научный «модульный» подход, который рассматривает совокупность объектов культурного наследия синхронно, как состоявшуюся целостность, и диахронно, как последовательность этапов его формирования, развития и в отдельных случаях утраты. В качестве модуля взята системная единица культурного ландшафта, представленная разнообразными таксономическими явлениями: культурными, социаль- ными, экономическими, природными и т.д. [9], [14].

Учитывая, что ценность рассматриваемых объектов неотделима от среды их существования, большое внимание уделяется поддержанию памяти о первоначальных культурных смыслах объекта и их последующей трансформации. Сохраненный или отреставрированный памятник старины, окруженный новостройками, становится либо пережитком прошлого, либо симулякром, отдаленно напоминающим прежний артефакт. Поэтому одна из важнейших задач сохранения культурного наследия - решить проблему «вписанности» объекта в современный ландшафт, особенно городской.

Именно поэтому в рамках нового подхода за основу берется пространство конкретного культурного ландшафта, представляющего собой связанный историко-культурный комплекс (модуль), самостоятельную единицу, обладающую своими территориальными, темпоральными, экономическими, культурными, семиотическими характеристиками. Такой подход уводит от точечного рассмотрения состояния отдельных памятников культуры, позволяя увязать этническую составляющую, культурный ландшафт и объекты культурного наследия в единое целое. В качестве модуля могут выступать целый городской район, историческое место, часть биосистемы, имеющие определенную функцию и конкретные параметры (пространственные, временные, смысловые и т.д.). Так, в городском культурном ландшафте Астрахани можно выделить несколько модулей - Кремль, Белый город, Заканалье, Закутумье, Косу, каждый из которых обладает культурным своеобразием [6], [13].

Гораздо больше культурных модулей в области. Часть таких комплексов относится к объектам федерального или регионального значения, как, например, Сарай-Бату (золотоордынский город около села Селитренное Харабалинского района), Хошеутовский хурул, построенный калмыцким князем Тюменем в честь победы над Наполеоном, остатки хазарских городов и сарматских поселений в низовьях Волги и др. Вопрос в том, что конкретно необходимо сохранить и в каком объеме. 
Коммерциализация объектов культурного наследия: проблемы и перспективы. Сегодня культурное наследие рассматривается не только как историческая ценность, несущая духовно-творческий потенциал, но и как ресурс, способный приносить доход. Однако для эффективного использования объектов культурного наследия нужна продуманная инфраструктура, сформированная с учетом инноваций, чтобы тот или иной памятник мог органично вписаться в экономический и социально-политические контексты.

На Западе активное использование объектов культурного наследия в экономике стало уже привычным, в то время как в России такая практика воспринимается с сомнением и подозрением. Между тем государственные финансовые вложения не могут охватить весь необходимый масштаб реставрационных работ. Множество ценных исторических памятников могут не дождаться своей очереди и исчезнуть. Следовательно, необходимо менять систему управления процессом сохранения культурного наследия и его использования. В качестве возможного выхода может рассматриваться создание цивилизованного рынка объектов культурного наследия, с разными формами государственно-частного партнерства (public-private partnership), предоставлением бизнесу более широких прав, включая «доверительное управление историко-культурными комплексами и недвижимостью сферы культуры (зданиями музеев, библиотек, театров и т.п.); безвозмездную передачу частному бизнесу объектов культурного наследия и культуры, находящихся в аварийном или руинированном состоянии с обеспечением их реставрации или капитального ремонта; проведение творческих конкурсов; создание частными инвесторами электронных библиотек, музеев, архивов и др.» [1, с.9], подключением к популяризации культурного наследия рекламных агентств и PR-служб, СMИ, кинематографа.

Следует только помнить, что вынужденное приспособление к существующему массовому спросу может примитивизировать смысловые категории и свести ценностные приоритеты до потребительского уровня. Часто реконструкция делает объект лишь при- близительным подобием подлинного артефакта или вообще превращает его «новодел». В Астрахани наиболее яркими примерами этого могут служить деревянный дом купца Тетюшинова, напоминающий сегодня новогоднюю игрушку, и Русское торговое подворье, снесенное до основания и заново выстроенное в стиле современной эклектики (сейчас это фешенебельная гостиница для VIP-гостей).

Культурное наследие становится «неисчерпаемым сырьем» $[8$, с. 62] для туристического бизнеса, тиражирования, имитаций и перформансов. В то же время такой симулякр способствует самоокупаемости культурного комплекса, создает новые рабочие места на малых предприятиях, воссоздающих исторические артефакты, что, несомненно, привлекает людей и усиливает их интерес к историческому прошлому края. Для ретрансляции знаний о прошлом в современном мире оказывается значимой именно экономическая составляющая культурного наследия, которая, как это ни парадоксально, помогает сохранить его культурную ценность.

Показателен в этом смысле образованный на основании Постановления губернатора Астраханской области от 27.05.2003 г. № 231 музейный археологический комплекс «Селитренное городище», более известный как Сарай-Бату, столица улуса Джучи (Золотая Орда). Комплекс находится в Харабалинском районе Астраханской области (территория городища - 2080 га) и является памятником археологии федерального значения. Это музей под открытым небом, объединяющий историческое и естественнонаучное направления. Здесь проводятся экскурсии, не прекращаются раскопки, ведутся научные исследования. После многолетних восстановительных работ стали доступны для посещения усадьбы золотоордынских аристократов, комплекс общественных зданий, большая мечеть, общественная баня, гончарные и стеклоделательная мастерские. Но, несмотря на такую значимость объекта, узнаваемым и знаменитым Сарай Бату стал после съемок фильма «Орда». Недалеко от настоящего древнего города для натурных съемок была «построена» глиняная столица Золотой Орды. К участию в картине привлекли жителей всех окрестных сел. Были 
задействованы даже местные верблюды. А вот юрту привезли из Монголии.

После съемок астраханские власти договорилось с «Мосфильмом» за небольшую плату оставить бутафорский город на том же месте и превратили его в культурно-развлекательный центр. «Киногород из пустых ящиков и глины» [15] превратился в культовый объект и «приманку» для туриста, который верит в подлинность увиденного. Экскурсоводы проводят гостей по улицам древнего города, рассказывают историю Золотой Орды, посетителей катают на верблюдах, а по праздникам проводят военно-исторические реконструкции и концерты. В местных кафе можно попробовать национальную кухню, а в сувенирных магазинчиках купить предметы «старины» и охранные амулеты далекой эпохи, воссозданные по старинным технологиям.

Астраханские туристические фирмы широко пользуются предоставленной возможностью привозить сюда гостей города. Был разработан тур «В гостях у хана» с посещением всех достопримечательностей, познавательной экскурсией и возможностью походить после неё по «восточному базару». Кроме того, все желающие могут сыграть в пейнтбол на специально оборудованной здесь для этого площадке. Между тем глиняный город является тем самым симулякром, который не отражает историческую реальность, а родился из фантазий художников, совместивших в декорациях азиатские и африканские мотивы. Однако это не смущает посетителей, которые убеждены, что именно благодаря съемкам фильма в Астраханской области появился исторический памятник [12].

Дискуссия и выводы. Культурное наследие Астраханской области уникально в силу своего поликультурного характера, что подтверждают и сохранившиеся до наших дней традиции разных народов, населяющих этот край, и архитектурный облик столицы и других городов региона, и многочисленные археологические находки. Но раскопки, реконструкция и обслуживание объектов культурного наследия требуют огромных капиталовложений. И хотя администрация об- ласти и города проводит большую работу по привлечению инвестиций, приезжие часто отмечают заброшенность многих исторических построек, находящихся на грани разрушения, в то время как при должном подходе они могли бы эффективно использоваться. И поскольку финансирования катастрофически не хватает, чаще создается культурный симулякр, который начинает использоваться как реальный объект культурного наследия. Память об исторических объектах понемногу уходит (особенно у молодого поколения), а симулякры остаются и замещают образовавшиеся лакуны. Это одна из сложнейших проблем сохранения культурного наследия сегодня.

С учетом современных реалий, можно предположить несколько сценариев дальнейшего развития сложившейся ситуации:

- пессимистический, ведущий к отчуждению объекта от культурного ландшафта с последующим его исчезновением;

- оптимистический, предполагающий наличие продуманной государственной культурной политики, привлечение общественности и развитие туристической сферы с сопутствующими ей секторами экономики;

- реалистический, констатирующий сокращение государственных программ, нацеленных на сохранение культурного наследия, и уменьшение ответственности государства за состояние и развитие культуры.

Модели государственно-частного сотрудничества дают хороший результат только при условии, если «и государственные структуры, и частный сектор проявляют достаточно гибкости для того, чтобы прокладывать новые пути и „творчески“ подходить к правовым ограничениям» [3, с.508]. Именно государству должна принадлежать ведущая роль во внедрении инвестиционных проектов с целью поддержания целостности культуры и сохранения культурного наследия России. Только в этом случае взаимодействие бизнеса и государства может стать эффективным механизмом реализации стратегических целей культурной политики, ориентированной на стабильное социокультурное развитие. Пока такого равновесия не наблюдается. 


\section{Svetlana V. KUNYASHOVA \\ Cultural Heritage of Astrakhan Oblast in the Regional Cultural Policy}

Abstract. The problem of preservation and effective use of the cultural heritage of a country is complex and multidimensional. In Russia, faced with a number of cardinal changes in various fields, including cultural, in the post-Soviet period, the problem is particularly acute. Its solution is one of the most important areas of cultural policy of the state and each of its individual regions. In this sense, the experience of the Lower Volga Region, a region representing a multicultural space, is interesting. On its example, the author of the article, using the method of cross-cultural analysis, examined the state of regional objects of cultural heritage and the possibility of their use. During the study, the specifics of the cultural heritage of Astrakhan Oblast, the history and features of the formation of an array of historical and cultural monuments located in the region were studied. Further, the prospects for using the cultural heritage of Astrakhan Oblast for regional economy's development were identified, examples of the reconstruction of historical objects in order to adapt them to mass tourist demand were studied. The author proposed a modular approach to the study of the cultural landscape and highlighted the basic modules of the cultural heritage of Astrakhan and Astrakhan Oblast. As a result, the author identified both positive trends characterising the regional cultural policy regarding the preservation and popularisation of cultural heritage and real problems, the unresolvedness of which sometimes leads to the complete disappearance of some objects due to their predatory exploitation or replacement by their simulacra. It is emphasised that simulacra replace the lacunae formed during the disappearance of memory of real historical objects. The author identifies three main scenarios that describe the fate of cultural heritage as a result of the application of certain measures of state regulation (pessimistic, optimistic and realistic). It is indicated that, in the Russian Federation, it is the state that should play a leading role in the implementation of investment projects in order to maintain the integrity of culture and preserve the cultural heritage of Russia. However, the state is not able to make financial investments that fully cover the full scale of restoration work. This actualises a change in the management system for the preservation of cultural heritage and its use. As a possible way out, creation of a civilised market of cultural heritage objects, with various forms of public-private partnership, provision of wider rights to business, can be considered.

Keywords: cultural heritage, cultural policy, multicultural region, simulacrum, cultural management, modular approach.

\section{Использованная литература:}

1. Белозор А. Ф. Взаимодействие государства и бизнеса в культурной политике России: автореф. дис. ... канд. культурологии. М., 2008.

2. Грант ФЦП (2012-2014) 2012-1.1-12-000-3003056 - «Научные и научно-педагогические кадры инновационной России» «Культурная память и культурное наследие фронтира» [Электронный ресурс] // Проект 4science. URL: https://4science.ru/project/14-B37-21-0029 (дата обращения 12.05.19).

3. Думбрава Е. А. Государственно-частное партнерство в культуре: суть явления и принципы внедрения // Современная культурная политика как креативная деятельность: управление и инновации. СПб: ЭЙдОС, 2014. С. 500-509.

4. Казакова Г. М. Регион как субкультурный локус: автореф.... д-ра культурологии. М., 2009.

5. Михайлов К. Национальный проект «Культура» [Электронный ресурс] // Хранители Наследия. URL: $\quad$ http://hraniteli-nasledia.com/articles/nasledie-

\section{References:}

1. Belozor, A.F. (2008) Vzaimodeystvie gosudarstva i biznesa $v$ kul'turnoy politike Rossii [The Interaction of the State and Business in the Cultural Policy of Russia]. Abstract of Culturology Cand. Diss. Moscow.

2. 4science. (2012) Grant FTsP (2012-2014) 2012-1.1-12-000-3003-056 - "Nauchnye i nauchnopedagogicheskie kadry innovatsionnoy Rossii" "Kul'turnaya pamyat' $i$ kul'turnoe nasledie frontira" [Grant of the Federal Target Program (2012-2014) 2012-1.1-12-000-3003-056 "Scientific and Scientific-Pedagogical Personnel of Innovative Russia" "Cultural Memory and Cultural Heritage of the Frontier"]. [Online] Available from: https://4science.ru/ project/14-B37-21-0029. (Accessed: 12.05.2019).

3. Dumbrava, E.A. (2014) Gosudarstvenno-chastnoe partnerstvo v kul'ture: sut' yavleniya i printsipy vnedreniya [Public-Private Partnership in Culture: The Essence of the Phenomenon and Principles of Implementation]. In: Astaf'eva, O.N. (ed.) Sovremennaya kul'turnaya politika kak kreativnaya deyatel'nost': upravlenie i innovatsii [Modern 
rossii/natsionalnyy-proekt-kultura-bez-kulturnogonaslediya/?sphrase_id=48349 (дата обращения 12.05.19).

6. Романова А. П. Белый город как модуль культурного ландшафта Астрахани // Каспийский регион: политика, экономика, культура. 2012. № 3. С. 236-242.

7. Романова А. П. Толерантное отношение к «Другому» в молодежной среде полиэтничного региона // Каспийский регион: политика, экономика, культура. 2010. № 4 (25). C. 15-20.

8. Романова А. П., Якушенков С. Н., Дахин С. А. Культурный менеджмент и политика сохранения культурного наследия // Человек. Сообщество. Управление. 2010. № 3. С. 58-62.

9. Романова А. П., Якушенков С. Н. Модульный подход в вопросе сохранения культурного наследия в рамках концепции культурного ландшафта // Каспийский регион: политика, экономика, культура. 2011. № 3. С. 258-265

10. Романова А. П. и др. Нижневолжский фронтир: культурная память и культурное наследие: уч. пособие. Астрахань: Сорокин Р. В., 2014.

11. Основные направления деятельности Правительства РФ на период до 2024 года [Электронный ресурс] // Правительство России. URL: http://government. $\mathrm{ru} / \mathrm{news} / 34168$ / (дата обращения 12.05.19).

12. Отзывы о Сарай-Бату [Электронный ресурс] // Трипадвизор. Россия. URL: https://www.tripadvisor.ru/ ShowUserReviews-g298513-d5617654-r203084446-Saraj_ Batu-Astrakhan.html (дата обращения 12.05.19).

13. Хлыщёва Е. В. Закутумье и Заканалье как культурный модуль // Каспийский регион: политика, экономика, культура. 2011. № 4. С. 288-294.

14. Хлыщёва Е. В. Проблема сохранения культурного наследия в поликультурном регионе // Известия ВГПУ. Сер. «Социально-экономические науки и искусство». 2012. № 8. С. 31-39.

15. Чем живет заброшенный киногород Сарай-Бату в Астраханской области. 2018 [Электронный ресурс] // Рамблер. URL: https://kino.rambler.ru/other/41173518chem-zhivet-zabroshennyy-kinogorod-saray-batu-vastrahanskoy-oblasti/ (дата обращения 12.05.19).

16. Foucault M. Of other spaces // Diacritics. Vol. 16. No. 1 (Spring, 1986). P. 22-27.

17. Howard P. Heritage: management, interpretation, identity. London: Continuum International Publishing, 2003.
Cultural Policy as a Creative Activity: Management and Innovation]. St. Petersburg: EYDOS. pp. 500-509.

4. Kazakova, G.M. (2009) Region kak subkul'turnyy lokus [Region as a Subcultural Locus]. Abstract of Culturology Dr. Diss. Moscow.

5. Mikhaylov, K. (2018) Natsional'nyy proekt "Kul'tura" [National Project "Culture"]. [Online] Available from: http://hraniteli-nasledia.com/articles/nasledierossii/natsionalnyy-proekt-kultura-bez-kulturnogonaslediya/?sphrase_id=48349. (Accessed: 12.05 .19 ).

6. Romanova, A.P. (2012) Belyy gorod kak modul' kul'turnogo landshafta Astrakhani [Bely Gorod as a Module of the Cultural Landscape of Astrakhan]. Kaspiyskiy region: politika, ekonomika, kul'tura - THE CASPIAN REGION: Politics, Economics, Culture. 3. pp. 236-242.

7. Romanova, A.P. (2010) Tolerantnoe otnoshenie $\mathrm{k}$ "Drugomu" v molodezhnoy srede polietnichnogo regiona [A Tolerant Attitude to the "Other" in the Youth Environment of a Multi-Ethnic Region]. Kaspiyskiy region: politika, ekonomika, kul'tura - THE CASPIAN REGION: Politics, Economics, Culture. 4 (25). pp. 15-20.

8. Romanova, A.P., Yakushenkov, S.N. \& Dakhin, S.A. (2010) Kul'turnyy menedzhment i politika sokhraneniya kul'turnogo naslediya [Cultural Management and the Policy of Preservation of Cultural Heritage]. Chelovek. Soobshchestvo. Upravlenie. 3. pp. 58-62.

9. Romanova, A.P. \& Yakushenkov, S.N. (2011) Modul'nyy podkhod $\mathrm{v}$ voprose sokhraneniya kul'turnogo naslediya $\mathrm{v}$ ramkakh kontseptsii kul'turnogo landshafta [A Modular Approach to the Preservation of Cultural Heritage in the Framework of the Concept of Cultural Landscape]. Kaspiyskiy region: politika, ekonomika, kul'tura - THE CASPIAN REGION: Politics, Economics, Culture. 3. pp. 258265

10. Romanova, A.P. et al. (2014) Nizhnevolzhskiy frontir: kul'turnaya pamyat' i kul'turnoe nasledie [The Lower Volga Frontier: Cultural Memory and Cultural Heritage]. Astrakhan: Sorokin R.V.

11. Government.ru. (2018) Osnovnye napravleniya deyatel'nosti Pravitel'stva RF na period do 2024 goda [The Main Activities of the Government of the Russian Federation for the Period up to 2024]. [Online] Available from: http:// government.ru/news/34168/. (Accessed: 12.05.2019).

12. Tripadvisor.ru. (2019) Otzyvy o Saray-Batu [Reviews on Sarai-Batu]. [Online] Available from: https:// www.tripadvisor.ru/ShowUserReviews-g298513d5617654-r203084446-Saraj_Batu-Astrakhan.html. (Accessed: 12.05.2019).

13. Khlyshcheva, E.V. (2011) Zakutum'e i Zakanal'e kak kul'turnyy modul' [Zakutumye and Zakanalye as a Cultural Module]. Kaspiyskiy region: politika, ekonomika, kul'tura - THE CASPIAN REGION: Politics, Economics, Culture. 4. pp. 288-294.

14. Khlyshcheva, E.V. (2012) Issue of Preservation of Cultural Heritage in the Polycultural Region. Izvestiya Volgogradskogo gosudarstvennogo pedagogicheskogo universiteta - Ivzestia of the Volgograd State PedagogicalUniversity. 8. pp. 31-39. (In Russian).

15. Rambler. (2018) Chem zhivet zabroshennyy kinogorod Saray-Batu $v$ Astrakhanskoy oblasti [How the Abandoned Film Town Saray-Batu Lives in Astrakhan Oblast]. [Online] Available from: https://kino.rambler.ru/ 
other/41173518-chem-zhivet-zabroshennyy-kinogorodsaray-batu-v-astrahanskoy-oblasti/. (Accessed: 12.05.2019). 16. Foucault, M. (1986) Of Other Spaces. Diacritics. 16(1). pp. 22-27.

17. Howard, P. (2003) Heritage: Management, Interpretation, Identity. London: Continuum International Publishing.

\section{Полная библиографическая ссылка на статью:}

Куняшова, С. В. Объекты культурного наследия Астраханской области в системе региональной культурной политики [Электронный ресурс] / С. В. Куняшова // Наследие веков. - 2019. - № 4. - C. 52-59. DOI: 10.36343/SB.2019.20.4.006

\section{Full bibliographic reference to the article:}

Kunyashova, S. V. (2019) Cultural Heritage of Astrakhan Oblast in the Regional Cultural Policy. Nasledie vekov - Heritage of Centuries. 4. pp. 52-59. (In Russian). DOI: 10.36343/SB.2019.20.4.006 